\title{
Effect of oxygen on the lungs after blast injury and burns
}

\author{
PS HASLETON, P PENNA, J TORRY \\ From the Departments of Pathology and Anaesthetics, University Hospital of South Manchester and \\ Department of Pathology, Royal Albert Edward Infirmary, Wigan
}

SUMMARY In March 1979 there was an explosion in a coalmine in Lancashire. As a result three men were found dead down the mine and a further seven men, all with extensive burns, died between the third and thirteenth day after the explosion. The lungs were studied in all the cases. Pulmonary infection was the commonest cause of death. Despite high levels of oxygen being given to these seven men, only one case showed a focal intra-alveolar fibrosis. In this case the inspired oxygen requirement came down before death. The toxicity of oxygen in the short term management of patients with severe trauma is questioned.

Golbourne is a Lancashire village lying midway between Wigan and Warrington. Nearly 900 men from the village and surrounding area work in the colliery.

On the night of 17th March 1979, a routine inspection revealed a breakdown in several ventilation fans in one of the development seams. The fan was only suspended by one chain and there was damage to the fan cable entry. The following day an eleven strong team was sent below to repair the fans. During this operation there was an electric spark between two exposed live connector pins. This spark ignited the firedamp that had built up during 10 to 15 hours when there had been no ventilation in the mine.

A sheet of fire spread down the mine followed by an explosion in the residual methane/air mixture. There was much damage. Three men were found dead and a further eight brought to the surface and transferred to the Burns Unit at Withington Hospital. Seven of these men died between the third and thirteenth day after the explosion.

During their stay in hospital the men were treated in the Intensive Care Unit. Oxygen formed one of the mainstays of treatment. The pulmonary changes found in all the patients, both those found dead and those dying in hospital, are described. In particular the relation between the amount of oxygen given and

Accepted for publication 27 April 1981 the development of pulmonary fibrosis is examined.

\section{Clinical details}

All the men were severely burnt. In most of the cases the burns were third degree. In addition there were multiple fractures, including a fractured skull in one case. The age of the cases, percentage of the body burnt and the main injuries are shown in the Table. A fuller description of the clinical, bacteriological and biochemical details will be presented elsewhere. ${ }^{1}$ A brief clinical summary is given here.

All the men admitted to hospital developed bacterial infections. It is significant that one case had Klebsiella aerogenes isolated from the throat on admission. All cases had one or all the following organisms isolated from the blood during treatment: Klebsiella aerogenes, Proteus mirabilis, Acinetobacter anitretum, Pseudomonas pyocyanea, Pseudomonas aeruginosa and two strains of Staphylococcus aureus, one genatamicin-sensitive, the other gentamicinresistant.

The blood urea was raised in all but one case (case 4) who died on day 3. One patient was haemodialysed three times. The platelet count was reduced in all patients. It was below $100 \times 10^{9} / 1$ in six patients and in one patient fell to below $15 \times 10^{9} / 1$. All the men needed platelet infusions and received steroids.

All patients were mechanically ventilated. The inspired oxygen was $30-100 \%$. The percentage of inspired oxygen in four patients is shown in Fig. 1. 
Details of cases and injuries sustained

\begin{tabular}{|c|c|c|c|c|c|}
\hline Case no & Age & $\begin{array}{l}\text { Percentage } \\
\text { burns }(\%)\end{array}$ & Fractures & Other injuries & $\begin{array}{l}\text { Day of death } \\
\text { (after explosion) }\end{array}$ \\
\hline 1 & 37 & 85 & \# ribs & Deep laceration left leg & FD \\
\hline 2 & 41 & 70 & $\begin{array}{l}\text { \# dislocation } \\
\text { left shoulder } \\
\text { \# ribs }\end{array}$ & $\begin{array}{l}\text { Pulmonary tear } \\
\text { Laceration of pulmonary trunk } \\
\text { Haemopericardium }\end{array}$ & FD \\
\hline 3 & 29 & 87 & $\begin{array}{l}\text { Depressed \# } \\
\text { post fossa }\end{array}$ & $\begin{array}{l}\text { Subdural haematoma } \\
\text { Laceration of dura } \\
\text { Laceration of both lower lobes }\end{array}$ & FD \\
\hline 4 & 44 & 85 & \# patella & $\begin{array}{l}\text { Cerebral oedema } \\
\text { Gastric erosions } \\
\text { Pulmonary tear }\end{array}$ & 3 \\
\hline 5 & 40 & 70 & - & $\begin{array}{l}\text { Laryngeal oedema } \\
\text { Acute tracheobronchitis }\end{array}$ & 4 \\
\hline 6 & 23 & 90 & $\begin{array}{l}\text { Supracondylar } \\
\text { \# humerus } \\
\text { \# ribs }\end{array}$ & $\begin{array}{l}\text { Subdural haemorrhage } \\
\text { Tracheobronchitis }\end{array}$ & 6 \\
\hline 7 & 41 & 85 & - & 一 & 8 \\
\hline 8 & 36 & 70 & 一 & $\begin{array}{l}\text { Tracheobronchitis } \\
\text { Myocardial abscesses }\end{array}$ & 8 \\
\hline 9 & 44 & 45 & 一 & $\begin{array}{l}\text { Tracheobronchitis } \\
\text { Pancreatitis }\end{array}$ & 13 \\
\hline 10 & 33 & 60 & \# patella & $\begin{array}{l}\text { Laryngotracheobronchitis } \\
\text { Cerebral oedema }\end{array}$ & 13 \\
\hline
\end{tabular}

FD = found dead. $\quad \#=$ fracture(d).

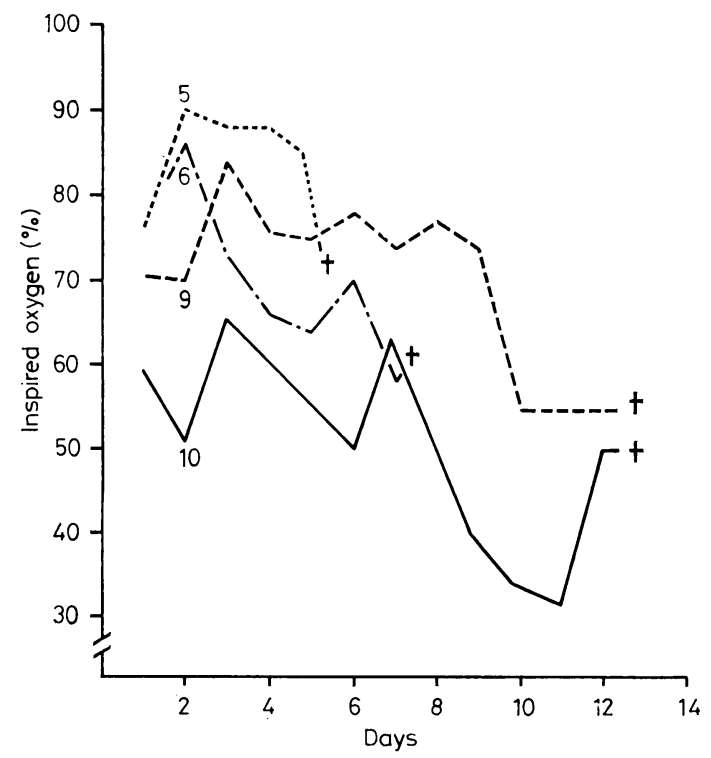

Fig. 1 Level of inspired oxygen in four of the cases treated in hospital.

PATHOLOGICAL FINDINGS

The cases can be split into two groups, those found dead down the mine and those who died in hospital. In each case two blocks of lung tissue were taken from each lobe and stained with haematoxylin and eosin and elastic van Gieson.

\section{Men found dead}

Three men were found dead in the mine. All three cases had fractures. In one case there was laceration of the pulmonary trunk with a haemopericardiume Macroscopically there was carbon pigment in the trachea and bronchial tree. In all cases there wasf evidence of marked congestion in one or both lobes of each lung. Two cases (cases 2 and 3) showed lacerations of the lungs. Case 1 showed a fine nodularity over the right lower lobe and some silicotic nodularity in the left upper lobe.

Histologically one case (case 1) showed minimal focal intra-alveolar oedema. In case 2 there was marrow and fat embolism in the muscular pulmonary arteries and pulmonary arterioles, some interstitial and intra-alveolar oedema as well as congestion of the alveolar wall. In some alveolar spaces there was green material, most probably bile, indicating aspiration of gastric contents. An interesting finding in case 2 was the presence of clumps of micro-organisms in some alveolar spaces as well as in the alveolar capillaries and muscular pulmonary arteries (Fig. 2). The last case found dead (case 3) had a pleural tear and also showed congestion of the alveolar wall with proliferation of the alveolar capillaries (Fig. 3) which extended into the alveolar lumina. There was pulmonary oedema and intraalveolar haemorrhage which was most prominent in the upper lobes.

Incidental findings unrelated to the explosion were centrilobular emphysema and small foci of fibrosis associated with carbon pigment. The mucous glands of the main bronchus showed hyperplasia. 


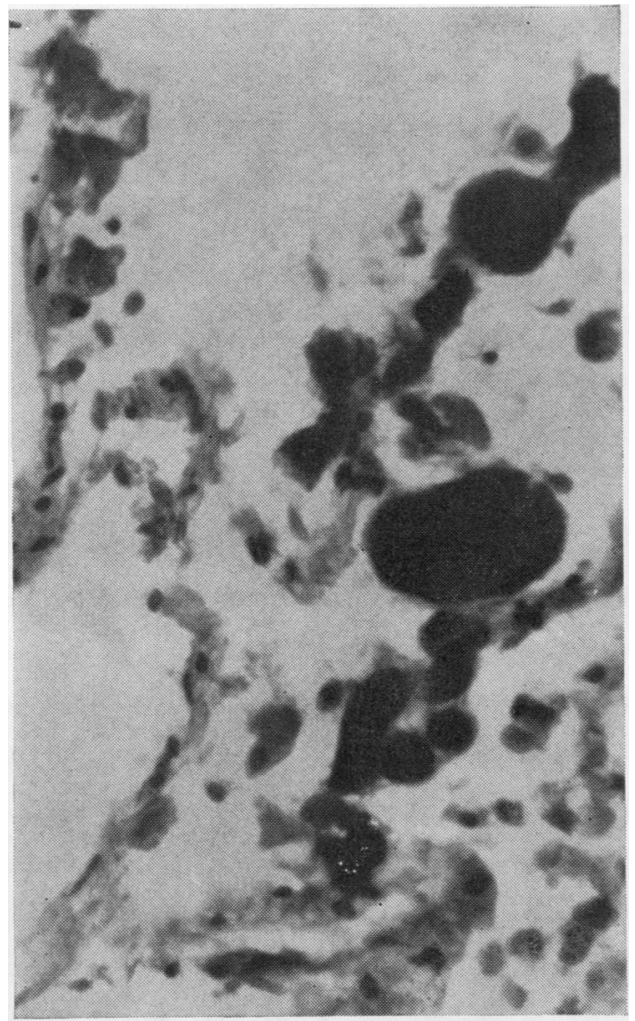

Fig. 2 Micro-organisms in pulmonary capillaries (case 2). Haematoxylin and eosin $\times 400$.
Men transferred to hospital

The changes in these seven cases can be classed in several pathological groups.

\section{(1) Infection}

All of the cases showed evidence of consolidation which involved, in most cases, every lobe. In two cases (cases 8 and 9) there was macroscopic evidence of multiple lung abscesses. Case 8 also showed ulceration of the mucous membrane in the bronchial tree.

\section{(2) Disseminated intravascular coagulation}

This was regarded as being present when giant endothelial cells were seen (Fig. 4). These cells were present in all but one case (case 7). In three cases (cases 7,8 and 10) there was evidence of microthrombi in pulmonary arteries and capillaries (Fig. 5). Hyaline membranes (Fig. 6) were present in three cases (cases 6,9 and 10) but were most pronounced in case 9.

(3) Changes in the alveolar wall and alveolar lumen Prominent interstitial oedema was present in 4 cases (cases 7, 8-10). Intra-alveolar oedema and haemorrhage were present in all cases. Marked congestion of the alveolar wall was also seen in all cases. In three cases (cases 7, 9 and 10) cuboidal epithelium lined the alveolar wall (Fig. 7) and in one case these cells formed a syncytium in the alveolar lumen. It is most likely that these cells were type II pneumocytes

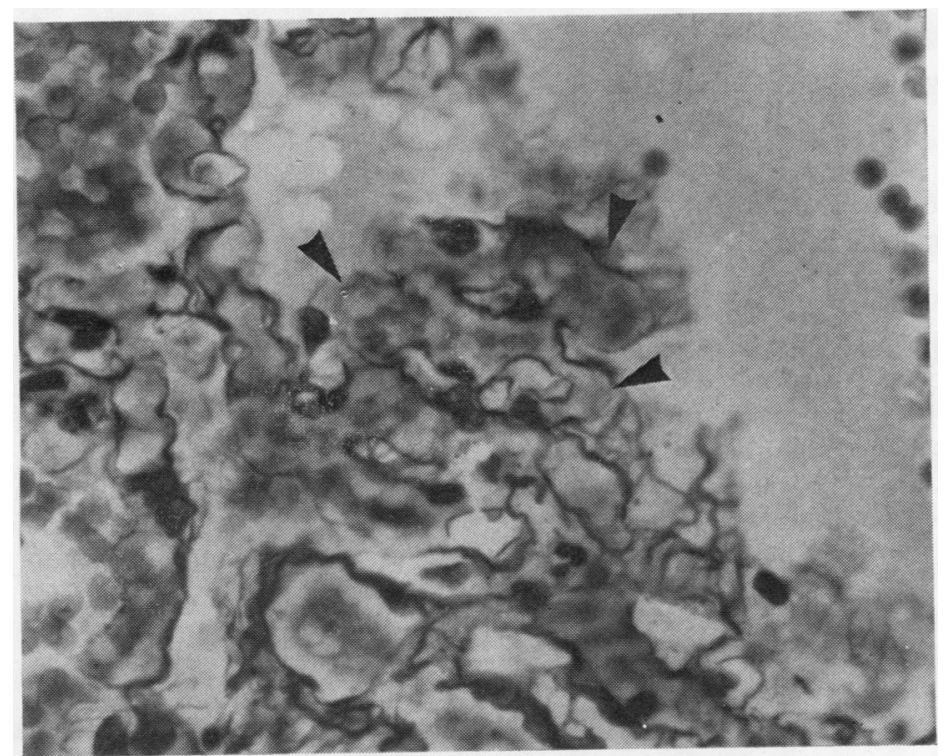

Fig. 3 Proliferation of alveolar capillaries (arrowed) (case 3). Foot's reticulin $\times 640$. 


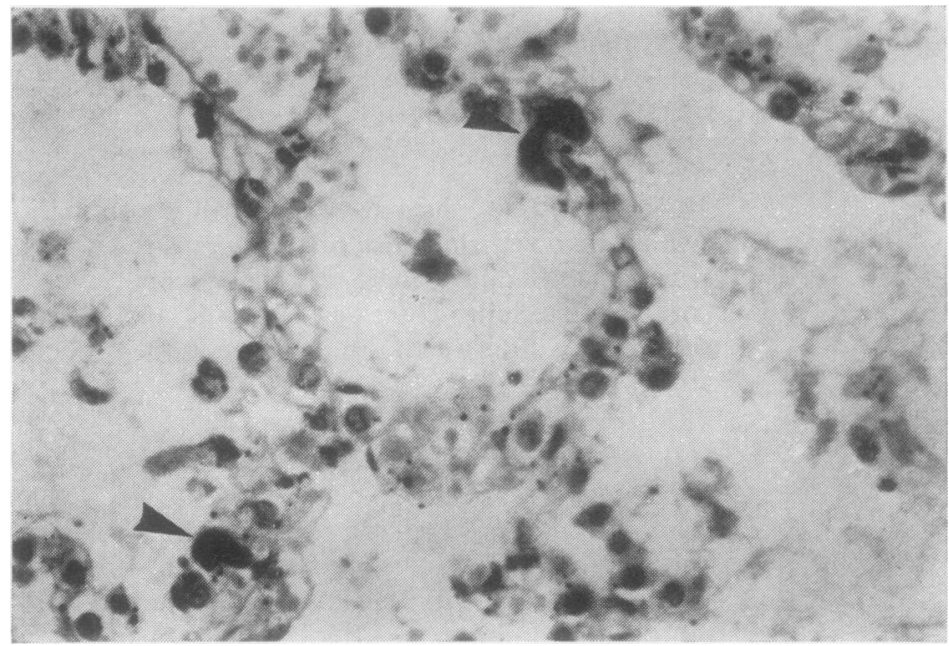

Fig. 4 Giant endothelial cells (arrowed) (case 10).

Haematoxylin and eosin $\times 400$.

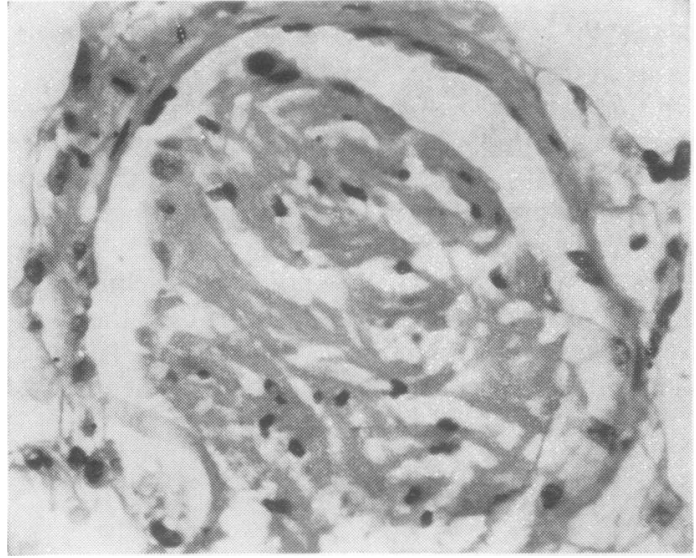

Fig. 5 Microthrombus in muscular pulmonary artery (case 7). Haematoxylin and eosin $\times 640$.

though with light microscopy it is not possible to differentiate these cells from alveolar macrophages.

\section{(4) Pulmonary fibrosis}

In two cases there were foci of old pulmonary fibrosis in the form of nodules with associated carbon pigmentation. Only one case (case 9) showed any recent fibrosis. This was detected in the hilar region of the lung macroscopically and histologically was seen focally in both upper lobes and the right middle lobe. The fibrosis was predominantly intra-alveolar (Fig. 7) though in the right upper lobe there was also interstitial fibrosis (Fig. 8). In some alveoli there was also intra-alveolar fibrin. Hyaline membranes were associated with the fibrosis as was the presence of cuboidal cells lining the alveolar wall.

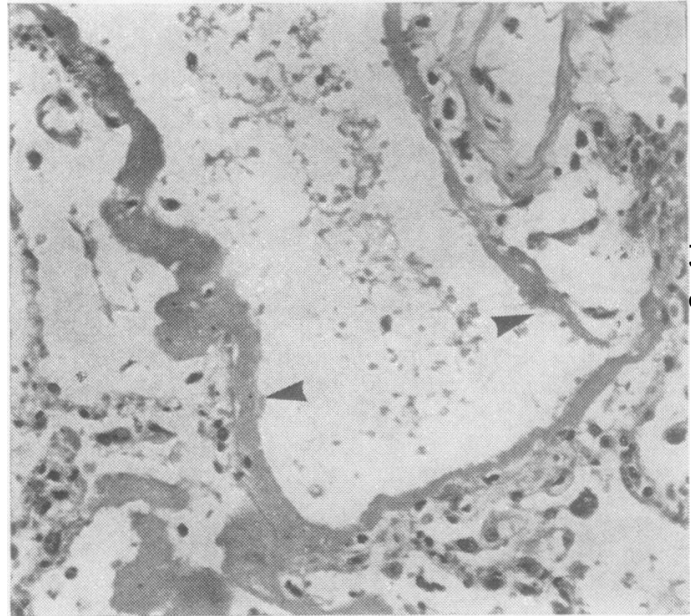

Fig. 6 Hyaline membrane (arrowed) involving alveolar duct and alveolus (case 9). Haematoxylin and eosin $\times 356$.

(5) Other pulmonary changes

Evidence of pulmonary infarction was seen in one case (case 8). In case 4 there was a laceration of the apex of the left lower lobe. Focal emphysema was present in two cases (4 and 9) and alveolar duct emphysema in two cases (6 and 8).

One case (case 5) showed focal granulomata in the alveolar wall. These showed no caseation and neither tubercle bacilli or fungi could be demonstrated. A diagnosis of early sarcoidosis was made.

\section{Discussion}

The present paper describes the pulmonary changes 


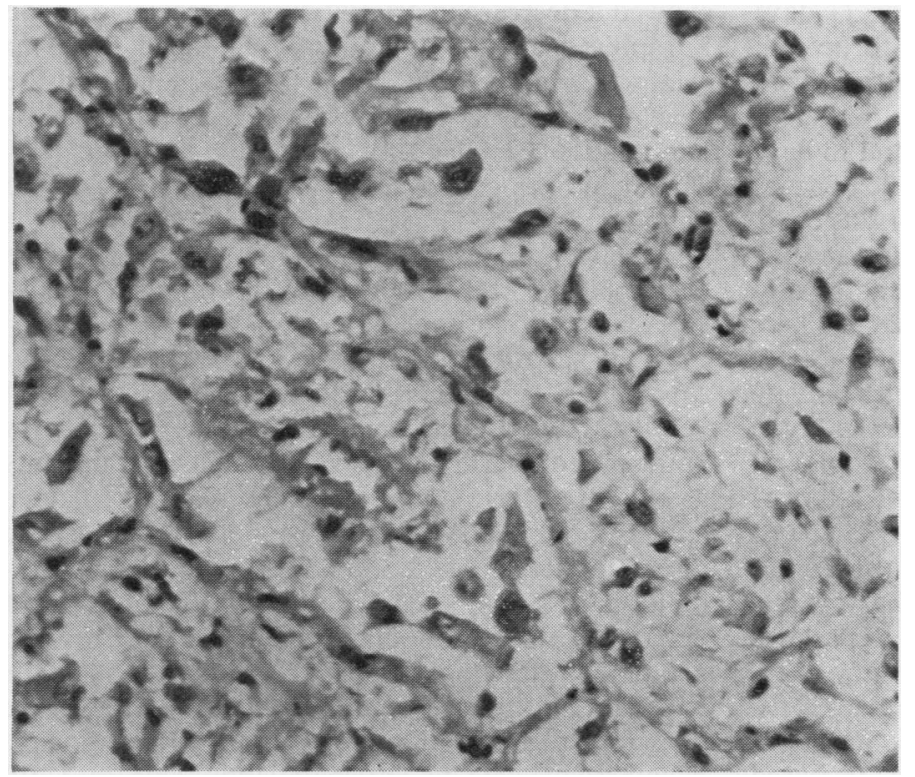

Fig. 7 Intra-alveolar fibrosis along with some cuboidal epithelial cells (case 9). Haematoxylin and eosin $\times 256$.

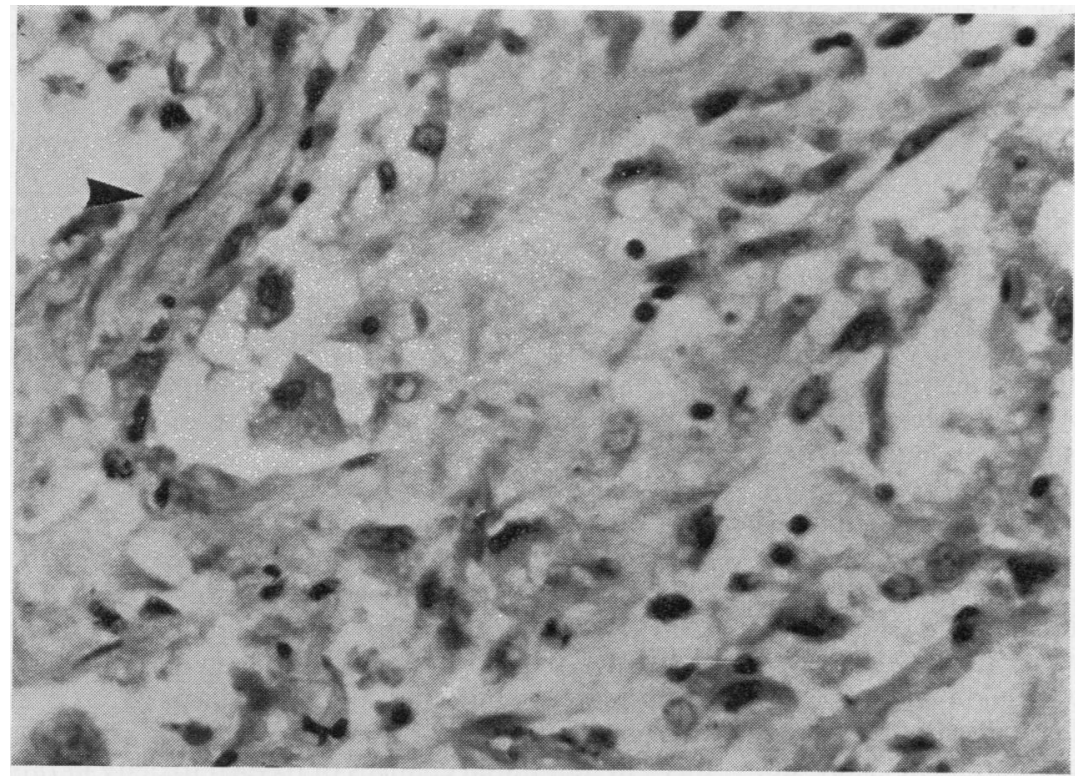

Fig. 8 Interstitial fibrosis (arrow) along with intra-alveolar fibrosis (case 9). Haematoxylin and eosin $\times 400$.

in a series of ten men who were exposed to severe blast injury and suffered extensive burns. The most important feature in the present study is a negative one, the lack of pulmonary fibrosis. Only one case (case 9) had evidence of pulmonary fibrosis which was both interstitial and intra-alveolar. It is interesting to note that the inspired oxygen concentration required by this patient decreased just before death, associated with treatment of his renal failure by haemodialysis. The dialysis presumably removed some of the pulmonary oedema. Had the fibrosis been severe and progressive, as might be expected in oxygen toxicity, then the inspired oxygen concentration should have increased.

Pulmonary fibrosis may not be the only criterion of pulmonary oxygen toxicity. Sevitt ${ }^{2}$ gave the criteria of hyaline membranes and proliferative pneumonitis as specific features of oxygen toxicity. 
He found intra-alveolar fibrosis as early as $2 \frac{1}{4}$ days after oxygen therapy though it appeared to be well established by 5 days. Hyaline membranes were present in only three of the present series (cases 6,9 and 10). These cases had oxygen for 6,13 and 13 days respectively. In the cases without hyaline membranes the duration of oxygen therapy was $1 \frac{1}{2}-8$ days. Hyaline membranes are not regarded as specific for oxygen toxicity by all authors. ${ }^{3-6}$ Bachofen and Weibel ${ }^{7}$ studied seven patients, three in detail. There was one case of pancreatitis, a case of pulmonary oedema following a fracture, complicated by bronchopneumonia and a case with multiple fractures. All patients were mechanically ventilated. One required an inspired oxygen concentration of $75 \%$. In the other two patients the inspired oxygen was kept below $45 \%$. Hyaline membranes were found in these three cases. The authors state that hyaline membranes are also present in the lungs of patients dying of respiratory distress due to other causes; fat embolism, drowning, viral pneumonia and sepsis. Other changes found were irregular widening of the interstitium due to oedema, fibrosis and increased cellularity and metaplasia of the alveolar lining cells into a cuboidal epithelium. These appearances were not thought to be due to oxygen toxicity since an inspiratory oxygen concentration of $40 \%$ is not toxic to man or animals. Other authors ${ }^{8} 9$ have emphasised that many of the changes of oxygen toxicity are non-specific.

Pratt $^{10}$ noted capillary proliferation as an early sign of oxygen therapy. However, we found capillary proliferation in one of the miners found dead and have seen it in burns cases not treated with oxygen and after myocardial infarction. Thus, as with the other histological features of oxygen therapy, proliferation of capillaries is an unreliable sign of oxygen toxicity. It is possible from Pratt's description that some of his cases may have had disseminated intravascular coagulation since he notes the presence of endothelial cells which are "usually rather large."

Pulmonary function studies have not helped to elucidate the problem of oxygen toxicity. Caldwell and Weibel ${ }^{11}$ thought that pulmonary oxygen toxicity develops in any person breathing oxygen $\left(\mathrm{PO}_{2}>700\right.$ torr) for longer than $6 \mathrm{~h}$. They do, however, say that oxygen toxicity is likely to occur in the patient with respiratory failure from some other cause and there is no way, in such patients, of assessing the contribution oxygen plays in the respiratory failure. Barber et al ${ }^{12}$ in a careful study investigated 10 patients with irreversible brain damage. Half the patients were ventilated with air and the rest with $100 \%$ oxygen. The first group were treated for a mean of $104 \mathrm{~h}$ (range $50-216 \mathrm{~h}$ ) and the oxygen group for a mean of $52 \mathrm{~h}$ (range 31-72 h). The oxygen group showed a decrease in arterial oxygen tension and the intrapulmonary shunt and ratio of dead space to tidal volume increased. These findings suggested the development of large areas of perfused but unventilated lung. Histology of the lung, however, was similar in both groups and hyaline membranes were absent in both groups. The elevation of the ratio of dead space to tidal volume could possibly be explained by the presence of disseminated intravascular coagulation (DIC).

In the same issue of the New England Journal of Medicine, Singer et al ${ }^{13}$ studied the effect of artificial ventilation with pure oxygen for up to seven days in patients after cardiac surgery. Though such patients are likely to have abnormal pulmonary vasculature and alveolar walls due to the underlying cardiac disease these authors found no difference in the intrapulmonary shunt, effective compliance, the ratio of dead space to tidal volume or clinical course when compared with controls. One case had oxygen for five days and recovered uneventfully. Another case died on the seventh day from intrapulmonary haemorrhage due to anticoagulants. This case did have early interstitial fibrosis and hyaline membranes. However, in the presence of congestive cardiac failure and pulmonary haemorrhage their significance is difficult to interpret. Van De Water eto $a l^{14}$ showed no changes in the alveolar/arteriak oxygen gradient, pulmonary artery pressure oro pulmonary resistance in a group of healthy young men exposed to oxygen for 6 to $12 \mathrm{~h}$. Comroe et al ${ }^{15}$ did a similar experiment for $24 \mathrm{~h}$ and with $50 \%$ oxygen produced no ill effects in the men studied. Astronauts can tolerate several weeks of pure oxygen at one third atmospheric pressure without showing any significant impairment of pulmonary gas exchange.

In one clinical study of blast lung ${ }^{16}$ two women developed pulmonary oedema. One of the patients received $100 \%$ oxygen for at least 25 days but the pulmonary changes apparently resolved and the patient was able to leave hospital. It has been postulated that it is the arterial oxygen tension which is of more significance than the inspired oxygen concentration. There is some experimental proof for this ${ }^{17}$ in that initial changes of oxygen toxicity in rats occur in endothelial cells.

We shall not deal with the experimental evidence in favour of oxygen toxicity as this has already been summarised. ${ }^{6}$ However, as these authors state there is interspecies variation in the oxygen susceptibility of the various alveolar cells and small animals are more susceptible to oxygen than large animals such as monkeys. It is still a big jump to equate the changes in monkeys' lungs due to oxygen with those in humans. 
The present study suggests that oxygen may not be as toxic, certainly over a period of 13 days, as has been previously suggested. In a sufficiently high concentration over a prolonged period of time oxygen may harm the lung but in the short term, based on the present study, if the patient's condition requires it, high inspired oxygen should be administered. The concentration of inspired oxygen required by the one case, with some focal pulmonary fibrosis, decreased before death probably due to haemodialysis. If a progressive fibrosing alveolitis had been occurring we would have expected an increased oxygen requirement. Any patient on oxygen is usually receiving it because there is some underlying pulmonary damage due, for example, to shock, trauma, fat embolism or disseminated intravascular coagulation. It may be that any of these processes render the lung more vulnerable to the effects of oxygen. In this study the lungs from the miners found dead were abnormal; there was pulmonary oedema, fat and marrow embolism and some interstitial oedema. Thus it is probable that there was underlying damage to the alveolar wall, due to the explosion.

It appeared that there were two distinct phases in the pulmonary changes as shown by the present series. In the three patients found dead there was intra-alveolar haemorrhage, oedema, interstitial oedema and, in one case, fat and marrow embolism. Such changes can be seen in animals exposed to blast injury. ${ }^{18}$ Similar changes, apart from the fat embolism, are present in patients with burns who have not received oxygen. It is interesting that in a short review of shock lung, ${ }^{19}$ Beyer describes in some cases, microthrombi and hyaline membranes. These were not present in our cases in the early stages of shock lung. It appears that the first changes in the lung after shock are vascular, probably because of a lack of nutrient flow. ${ }^{52021}$ As a consequence of this there is increased permeability of the basement membranes which will give rise to intra-alveolar and interstitial oedema. Surfactant production is reduced. Both endothelial and alveolar cells are damaged and this may lead to hyaline membrane formation.

The presence of intra-alveolar oedema, focal atelectasis and lack of pulmonary surfactant as well as extensive burns sets the scene for pneumonia which was present in all cases who died in hospital. It is interesting that in one of the patients found dead, organisms were present in the lung. These were carried in the pulmonary vasculature though we cannot entirely rule out a primary colonisation of the lung. It is interesting that a Klebsiella was grown from a throat swab taken on admission from one of the miners sent to hospital.
Associated with the infection, or perhaps preceding it, was evidence of disseminated intravascular coagulation. This is manifest by the formation of globular hyaline microthrombi and giant endothelial cells. These latter cells are regarded by some authors 2122 as megakaryocytes. The former authors rarely found these cells in the spleen, liver and kidney. There was a significant correlation with the presence of such cells and intravascular coagulation in cases dying of acute infections, cirrhosis, cancer and shock. It should be noted that "megakaryocytes" though found in control cases are present in smaller numbers. The Aberdeen group ${ }^{23}$ regard these cells, both on light and electron microscopy, as endothelial cell nuclei and not megakaryocytes. They give them the name "haematoxylinophil bodies." Support for the endothelial cell origin comes from rabbits given Escherichia coli endotoxin. ${ }^{24}$ In these animals large numbers of endothelial cells were seen in the blood within minutes of injection of low doses of endotoxin.

We wish to thank Mr DP Blakey, HM Coroner for Greater Manchester County (West) for permission to report these cases.

\section{References}

${ }^{1}$ Penna P, Hey V, Orton C, Hasleton PS. 1981; In preparation.

${ }^{2}$ Sevitt S. Diffuse and focal oxygen pneumonitis; a preliminary report on the threshold of oxygen toxicity in man. J Clin Pathol 1974;27:21-30.

${ }^{3}$ Martin AM Jr, Soloway HB, Simmons RL. Pathologic anatomy of the lungs following shock and trauma. J Trauma 1968;8:687-98.

${ }^{4}$ Bredenberg CE, James PM, Collins J, Anderson RW, Martin AM Jr, Hardaway RM. Respiratory failure in shock. Ann Surg 1969;169:392-403.

${ }^{5}$ Blaisdell FW, Lun RC, Stallone RJ. The mechanism of pulmonary damage following traumatic shock. Surg Gynecol Obstet 1970;130:15-22.

- Katzenstein A-LA, Bloor CM, Leibow AA. Diffuse alveolar damage- the role of oxygen, shock and related factors: a review. Am J Pathol 1976;85:210-28.

' Bachofen M, Weibel ER. Basic pattern of tissue repair in human lungs following unspecific injury. Chest suppl $1974 ; 65: 14$ S-9S.

${ }^{8}$ Deneke SM, Fanburg BL. Normobaric oxygen toxicity of the lung. $N$ Engl J Med 1980;303:76-86.

- Wolfe WG, DeVries WC. Oxygen toxicity. Annu Rev Med 1975;26:203-17.

${ }^{10}$ Pratt PC. Pulmonary capillary proliferation induced by oxygen inhalation. Am J Pathol 1958;34:1033-49.

${ }^{11}$ Caldwell PRB, Weibel ER. In: Fishman AP, ed. Pulmonary oxygen toxicity in pulmonary diseases and disorders. New York: McGraw Hill, 1980;800-5.

12 Barber RE, Lee J, Hamilton WK. Oxygen toxicity in man; a prospective study in patients with irreversible brain damage. $N$ Engl J Med 1970;283:1478-84.

${ }^{13}$ Singer MM, Wright F, Stanley LK, Roe BB, Hamilton WK. Oxygen toxicity in man; a prospective study in patients after open-heart surgery. $N$ Engl J Med 1970;283:1 473-8. 
14 Van De Water JM, Kagey KS, Miller IT et al. Response of the lung to six to 12 hours of $100 \%$ oxygen inhalation in normal man. $N$ Engl J Med 1970;283:621-6.

${ }^{15}$ Comroe JH Jr, Dripps RD, Dumke PR, Deming $M$. Oxygen toxicity: the effect of inhalation of high concentrations of oxygen for twenty-four hours on normal men at sea level and at a simulated altitude of 18000 feet. JAMA 1945;128:710-7.

${ }^{16}$ McCaughey W, Coppel DL, Dundee JW. Blast injuries to the lungs; a report of two cases. Anaesthesia $1973 ; 28$ 2-9.

${ }^{17}$ Kistler GS, Caldwell PRB, Weibel ER. Development of fine structural damage to alveolar and capillary lining cells in oxygen-poisoned rat lungs. $J$ Cell Biol 1967;32: 605-28.

18 Zuckerman S. Experimental study of blast injuries to the lungs. Lancet 1940;ii:219-24.

19 Beyer A. Shock lung. Br J Hosp Med 1979;21:248-59.

${ }^{20}$ Vieth FJ, Sinha SBP, Graves JS, Boley SJ, Dougherty JC.
Ischaemic tolerance of the lung. The effect of ventilation and inflation. $J$ Thorac Cardiovasc Surg 1971;61:804-10.

21 Corrin B. Lung pathology in septic shock. J Clin Pathol $1980 ; 33: 891-4$.

${ }_{22}$ Aabo K, Hansen KB. Megakaryocytes in pulmonary blood vessels. 1. Incidence at autopsy, clinico-pathological relations especially to disseminated intravascular coagulation. Acta Pathol Microbiol Scand [A] 1978;86: 285-91.

${ }^{23}$ Brown LT, Stalker AL, Hall J. Experimental defibrination II Histological studies by light and electron microscopy. Microvasc Res 1969;1:295-307.

${ }^{24}$ Gaynor E, Bouvier CA, Spaet TH. Circulating endothelial cells in endotoxin treated rabbits. Clin Res 1968;16:535.

Requests for reprints to: Dr PS Hasleton, Department of Histopathology, Withington Hospital, West Didsbury, Manchester M20 8LR, England. 